\title{
Guest Editorial: Spatial demography in regional science
}

\author{
Rachel S. Franklin ${ }^{1}$ (D) Jacques Poot $^{2}$
}

Received: 6 May 2021 / Accepted: 6 May 2021 / Published online: 15 May 2021

(c) The Author(s), under exclusive licence to Springer-Verlag GmbH Germany, part of Springer Nature 2021

During the last 15 years, there has been growing interest in the field of spatial demography (e.g., Raymer et al. 2019). This has been prompted by demographers returning, after several decades of emphasis on microdemography, to the core issue of the distribution of population at various spatial scales (see, e.g., Voss 2007). In fact, a special Springer journal, Spatial Demography, was started in 2013 to cater to this scientific trend. The spatial-temporal dynamics of population size and composition is of course also an important topic in several other disciplines, such as geography, sociology, and economics. Spatial demography features therefore also extensively in interdisciplinary fields such as regional science, which emerged in the 1950s. Indeed, the opening chapters of Walter Isard's 1960 Methods of Regional Analysis focused on regional population change and migration, while Andrei Rogers' 1968 Matrix Analysis of Interregional Population Growth and Distribution provided the first systematic framework for multiregional demographic analysis. Ever since, sessions on population and migration have been a stalwart component of virtually all regional science conferences-providing many innovations and insights into the study of spatial population dynamics. This special issue presents a selection of topics that have been covered in recent years. Not surprisingly, the set of papers reflect contemporary demographic concerns such as population aging, depopulation, immigration, local residential mobility, and ethnic diversity.

In the opening paper, Verena McClain and Brigitte Waldorf show that the life table and cohort analysis - core concepts of demography - fit within the broad family of longitudinal methods in which space and time are mathematically similar variables (both nonnegative and real). This then leads to the idea of spatial hazard (such as mobility and migration) being the counterpart of temporal hazard (such as survivorship). The growth of georeferenced digital trace data provides an emerging opportunity to test this approach in mobility and migration studies (e.g., Fiorio et al. 2021). As the authors show, longitudinal methods need not be constrained

Rachel S. Franklin

rachel.franklin@newcastle.ac.uk

1 Centre for Urban and Regional Development Studies (CURDS), School of Geography, Politics and Sociology, Newcastle University, Newcastle upon Tyne NE1 7RU, UK

2 National Institute of Demographic and Economic Analysis (NIDEA), University of Waikato, Hamilton, New Zealand 
to individuals and groups: the longitudinal transition of areas like neighborhoods is also a possible, but underexploited, extension.

The second paper shows how spatial autocorrelation and spatial econometric modelling are natural tools to investigate subnational differences in demographic indicators. Jeroen Spijker, Joaquin Recaño, Sandra Martínez, and Alessandra Carioli demonstrate demographic space-time interdependence with a spatial-econometric analysis of mortality by cause in the municipalities of Colombia. They identify several contextual variables and the presence of mortality clusters that can inform spatially differentiated policies aiming at increasing survivorship.

A pervasive trend in the developed world is that of depopulation in an increasing fraction of regions and cities, even in countries where national populations are still growing. The primary causes are sub-replacement fertility, population aging and net outward migration. Using data on US cities, Rachel Franklin focuses in the third paper of this special issue on the communities that experience population loss. She discovers notable differences in demographic composition between areas of population gain and loss, but also within areas of population loss. She finds that the burden of decline falls predominantly on the poor and on the Black population, both at the city level and at the census tract level.

It is tempting to think of controlled immigration as the policy instrument through which population loss can be reduced or even averted. Many studies have shown that immigration cannot be a long-term solution to population aging and loss, primarily because fertility patterns of immigrant communities often show convergence to the sub-replacement fertility of the destination country (e.g., Poot 2008). Nonetheless, the anticipated contribution to population growth was one argument in favor of Germany's acceptance of close to a million Syrian refugees (one out of six of the total Syrian diaspora) since 2015. However, Niall Newsham and Francisco Rowe show in the fourth paper, using Bayesian probabilistic projections, that Syrian immigration cannot be a solution to Germany's population decline, even though this migration has an upward effect on the total fertility rate.

Even more so than cross-border movement, subnational residential mobility has been a core area of regional science research. While historical data have tended to enable the study of ex post (re)settlement, in recent years the focus has shifted to studying the desire or intention to change location. Eveline van Leeuwen and Viktor Venhorst use a pooled set of housing demand surveys in the Netherlands to show that households had an increasing desire to move down the urban hierarchy following the 2008 Global Financial Crisis, i.e., from central cities to suburbs or provincial centers. Van Leeuwen and Venhorst expect that mobility patterns following the current COVID-19 pandemic may generate similar patterns. This hypothesis clearly warrants careful testing in the years to come.

The final paper of the special issue continues the theme of residential mobility by focussing on its impact in terms of spatial sorting, i.e., the non-random spatial clustering of socioeconomic groups. Mohana Mondal, Michael Cameron and Jacques Poot use entropy-based measures of sorting and of neighborhood diversity to investigate cultural and economic residential sorting in Auckland, New Zealand. They find that sorting is stronger in terms of ethnicity than in terms of economic characteristics. Additionally, sorting patterns display increasing heterogeneity. 
It is not too hard to speculate on some possible directions of future contributions of regional scientists to the study of spatial population dynamics. The rapidly evolving big data environments and new techniques to study space-time processes offer much scope, although there are pitfalls (see Cesare et al. 2018). We also expect greater use of stochastic sub-national population projection methodologies for heterogeneous populations. Bayesian methods are likely to become more prominent in this endeavor (e.g., Bijak and Bryant 2016). Further use of the tools of spatial statistics and econometrics (viz., Geographically Weighted Regression, GIS, multilevel modelling, spatial point processes and remote sensing) may also be expected. Furthermore, modelling may benefit from artificial intelligence methods and machine learning for complex space-time data analysis (e.g., Molina and Garip 2019). Integrated public data infrastructures, that link administrative data from many sources, high-dimensional geo-referenced data from mobile phones and internet-based data on mobility can be particularly helpful in studying geographic mobility (e.g., Fiorio et al. 2021). Finally, a greater focus may be expected on networks and spatial interactions (e.g., Small and Adler 2019). Thus, new developments in spatial demography may contribute to a better understanding of core demographic processes of fertility, morbidity, mortality, and geographic mobility-as well as the growing compositional diversity of populations - at a wide range of spatial scales.

In summary, we expect that — as it has been since the birth of the field - the spatial-temporal study of population will continue to feature at the center of future conferences and publications in regional science.

Acknowledgements The guest editors of this special issue would like to thank Associate Editor Petra Staufer-Steinnocher and Editor-in-Chief Manfred Fischer for their encouragement and support in the development of this special issue.

\section{References}

Bijak J, Bryant J (2016) Bayesian demography 250 years after Bayes. Popul Stud 70(1):1-19

Cesare N, Lee H, McCormick T, Spiro E, Zagheni E (2018) Promises and pitfalls of using digital traces for demographic research. Demography 55:1979-1999

Fiorio L, Zagheni E, Abel G, Hill J, Pestre G, Letouzé E, Cai J (2021) Analyzing the effect of time in migration measurement using georeferenced digital trace data. Demography 58(1):51-74

Isard W (1960) Methods of regional science: an introduction to regional science. MIT Press, Cambridge

Molina M, Garip F (2019) Machine learning for sociology. Ann Rev Sociol 45:27-45

Poot J (2008) Demographic change and regional competitiveness: the effects of immigration and ageing. Int J Foresight Innov Policy 4(1-2):129-145

Raymer J, Willekens F, Rogers A (2019) Spatial demography: a unifying core and agenda for further research. Popul Space Place 25(4):e2179

Rogers A (1968) Matrix analysis of interregional population growth and distribution. University of California Press, Berkeley

Small ML, Adler L (2019) The role of space in the formation of social ties. Ann Rev Sociol 45:111-132

Voss P (2007) Demography as a spatial social science. Popul Res Popul Rev 26(5-6):457-476

Publisher's Note Springer Nature remains neutral with regard to jurisdictional claims in published maps and institutional affiliations. 